THEORY AND METHODS

\title{
Psychosocial work environment and myocardial infarction: improving risk estimation by combining two complementary job stress models in the SHEEP Study
}

\author{
R Peter, J Siegrist, J Hallqvist, C Reuterwall, T Theorell, and the SHEEP Study Group
}

J Epidemiol Community Health 2002;56:294-300

See end of article for authors' affiliations

\section{Correspondence to:}

Dr R Peter, Department of Medical Sociology,

University of Ulm, Am

Hochstraess 8, D-89081

Ulm, Germany;

richard.peter@

medizin.uni-ulm.de

Accepted for publication

7 September 2001
Objectives: Associations between two alternative formulations of job stress derived from the effort-reward imbalance and the job strain model and first non-fatal acute myocardial infarction were studied. Whereas the job strain model concentrates on situational (extrinsic) characteristics the effortreward imbalance model analyses distinct person (intrinsic) characteristics in addition to situational ones. In view of these conceptual differences the hypothesis was tested that combining information from the two models improves the risk estimation of acute myocardial infarction.

Methods: 951 male and female myocardial infarction cases and 1147 referents aged 45-64 years of The Stockholm Heart Epidemiology (SHEEP) case-control study underwent a clinical examination. Information on job stress and health adverse behaviours was derived from standardised questionnaires.

Results: Multivariate analysis showed moderately increased odds ratios for either model. Yet, with respect to the effort-reward imbalance model gender specific effects were found: in men the extrinsic component contributed to risk estimation, whereas this was the case with the intrinsic component in women. Controlling each job stress model for the other in order to test the independent effect of either approach did not show systematically increased odds ratios. An improved estimation of acute myocardial infarction risk resulted from combining information from the two models by defining groups characterised by simultaneous exposure to effort-reward imbalance and job strain (men: odds ratio 2.02 (95\% confidence intervals (Cl) 1.34 to 3.07$)$; women odds ratio $2.19(95 \% \mathrm{Cl} 1.11$ to 4.28$))$.

Conclusions: Findings show an improved risk estimation of acute myocardial infarction by combining information from the two job stress models under study. Moreover, gender specific effects of the two components of the effort-reward imbalance model were observed.
D uring the past decades two theoretical models measuring stressful psychosocial work environment have been developed and tested with particular intensity: the job strain model and the model of effort-reward imbalance.

The well known job strain model assumes that exposure to work places with a specific task profile (high demands in combination with low decision latitude) contributes to stress related cardiovascular risk and disease. ${ }^{1-5}$ Job strain was found to be associated with coronary heart disease in many prospective studies (for overview see references ${ }^{36}$ ). Alternatively, the effort-reward imbalance model maintains that lack of reciprocity between efforts spent and rewards received (that is, high "cost"/low "gain" conditions) in a core social role, the work role, defines a state of emotional distress with special propensity to autonomic arousal and neuroendocrine response. $^{7}$ Two components of efforts and rewards are distinguished in the model: an extrinsic component mirroring distinct job conditions (effort: demands, obligations; rewards: money, esteem, career opportunities, and security), and an intrinsic component, the personal coping style termed "overcommitment". "Overcommitment" defines a set of attitudes, behaviours, and emotions reflecting excessive striving in combination with a strong desire of being approved and esteemed. People characterised by "overcommitment" are exaggerating their efforts beyond levels usually considered appropriate. Effort-reward imbalance was shown to be associated with coronary risk and disease in two prospective ${ }^{89}$ and several cross sectional (for overview see Peter and Siegrist ${ }^{10}$ ) studies.

While there is some overlap between the two models with respect to the demand component, they clearly differ in two regards: firstly, the job strain model is restricted to the situational aspects of the psychosocial work environment whereas the effort-reward imbalance model includes both extrinsic (situational) and intrinsic (person) characteristics. Secondly, by focusing on salaries, promotion prospects and job stability, among others, the latter model more explicitly links stressful experience at work with broader labour market conditions. Therefore, a combination of information derived from the two models may capture a broader range of stressful experience at work and, thus, result in an improved risk estimation of stress related disease onset.

More recently gender (role) specific effects of psychosocial work environment on cardiovascular health were studied, emphasising the specific role of employed women (double exposure, less career continuity). ${ }^{11}{ }^{12}$ Taking into account these gender specific effects it may well be that the components of the job stress models mentioned above exert differential impact on health according to gender roles. For instance, in a previous report we found stronger effects on cardiovascular risk factors produced by the intrinsic component of the effortreward imbalance model in women compared with men. Conversely, stronger effects of the extrinsic component were observed in men. ${ }^{13}$ This difference, to some extent, may reflect gender-role related value preference (for example, high value assigned to occupational status control in male gender role (as measured by extrinsic reward components). Therefore, we test the hypothesis of differential impact on disease risk produced by the two components of the effort-reward imbalance model (extrinsic versus intrinsic) in men versus women. 
Table 1 Sociodemographic variables, coronary risk factors, indicators of job stress, and myocardial infarction (men and women aged 45-64 years) (percentage of exposed (valid numbers/missing data) or mean (SD) value (valid numbers/missing data) in cases and referents)

\begin{tabular}{|c|c|c|}
\hline & Cases $(n=951)$ & Referents $(n=1147)$ \\
\hline Age (y) & $55.8(5.5)(951 / 0)$ & $55.9(5.5)(1147 / 0)$ \\
\hline Gender (male) & $74.7 \%(710 / 0)$ & $73.1 \%(838 / 0)$ \\
\hline Education (<12 years) & $72.6(681 / 13)$ & $64.0 \%(728 / 9)$ \\
\hline Socioeconomic group (blue collar) & $35.9 \%(258 / 232)$ & $24.3 \%(224 / 227)$ \\
\hline Systolic blood pressure (mm Hg) & 128.4 (18.8) (837/114) & $136.9(20.1)(1021 / 126)$ \\
\hline Diastolic blood pressure $(\mathrm{mm} \mathrm{Hg})$ & $79.8(10.1)(838 / 113)$ & 83.9 (10.7) (1020/127) \\
\hline Total cholesterol (mg/dl) & $240.1(45.8)(836 / 115)$ & 227.3 (39.6) (1019/128) \\
\hline LDL-cholesterol (mg/dl) & $163.6(39.4)(805 / 146)$ & 153.1 (37.0) (1009/138) \\
\hline HDL-cholesterol (mmol /l) & $1.1(0.3)(824 / 127)$ & $1.3(0.4)(1011 / 136)$ \\
\hline Body weight $\left(\mathrm{kg} / \mathrm{m}^{2}\right)$ & $27.0(4.0)(833 / 118)$ & $25.8(3.8)(1019 / 128)$ \\
\hline Cigarette smoking (mean number/day) & $11.5(9.1)(951 / 0)$ & $6.7(7.6)(1047 / 0)$ \\
\hline Hypertension (yes) & $36.7 \%(322 / 114)$ & $30.3 \%(318 / 127)$ \\
\hline \multicolumn{3}{|l|}{ Smoking status: } \\
\hline current & $59.2 \%(563 / 0)$ & $31.4 \%(360 / 0)$ \\
\hline former & $22.8 \%(217 / 0)$ & $31.4 \%(360 / 0)$ \\
\hline never & $18.0 \%(171 / 0)$ & $37.2 \%(427 / 0)$ \\
\hline Family history of CHD (yes) & $53.3 \%(507 / 0)$ & $38.5 \%(442 / 0)$ \\
\hline Diabetes (yes) & $14.2 \%(134 / 5)$ & $3.9 \%(45 / 3)$ \\
\hline Lack of physical exercise (<1/week) & $73.5 \%(697 / 3)$ & $62.3 \%(712 / 4)$ \\
\hline \multicolumn{3}{|l|}{ Effort-reward imbalance } \\
\hline effort-reward-ratio $(>1)$ & $21.1 \%(192 / 40)$ & $16.8 \%(186 / 37)$ \\
\hline overcommitment (upper tertile) & $35.0 \%(314 / 54)$ & $26.9 \%(296 / 47)$ \\
\hline Job strain (upper quartile) & $35.4 \%(324 / 35)$ & $27.2 \%(307 / 20)$ \\
\hline \multicolumn{3}{|c|}{ Simultaneous exposure to job strain and to effort-reward imbalance } \\
\hline Job strain present and effort-reward-ratio $>1$ & $12.8 \%(115 / 55)$ & $8.7 \%(96 / 46)$ \\
\hline $\begin{array}{l}\text { Job strain present and overcommitment present } \\
\text { (upper tertile) }\end{array}$ & $16.2 \%(142 / 74)$ & $10.9 \%(119 / 59)$ \\
\hline
\end{tabular}

In this report two research questions are analysed: firstly, as mentioned, we investigate whether gender specific associations between different components of stressful psychosocial work environment and acute myocardial infarction are present. Secondly, we explore to what extent a combination of information from both models, the job strain model and the effort-reward imbalance model, improves the risk estimation of first non-fatal acute myocardial infarction.

\section{METHODS}

The Stockholm Heart Epidemiology Programme (SHEEP) investigation is a population based case-referent study on factors associated with acute myocardial infarction. The study base comprised all male and female residents living in Stockholm county and aged 45-70 years. Cases were all persons with first fatal or non-fatal acute myocardial infarction between January 1992 and January 1994 (men) and between January 1992 and December 1994 (women) according to specified diagnostic criteria including information on symptoms, electrocardiogram, blood chemistry, and necropsy findings. Cases were identified by 10 cardiology units of emergency hospitals each covering a defined area and from death records for fatal cases who died outside hospitals. Referents were chosen from computerised registers of the county population at the same time as cases. Referents were matched by age, gender, and hospital catchment area. One referent per case was included and non-responding referents were substituted for in order to obtain at least one referent for each of the 2246 identified cases. A more detailed description of the study design and methods is available from Reuterwall et al. ${ }^{14}$

The present analysis was restricted to employed surviving cases and referents aged 45-64 years. This age group was chosen as relations between adverse psychosocial work environments and cardiovascular risk are expected to be strongest before the age of 65 years. ${ }^{75}$ Moreover, only non-fatal cases were included because of the fact that information on psychosocial exposure and health related risks was obtained from standardised questionnaires (see below). Thus, the present sample consists of 951 cases and 1147 referents. Response rates were $77.8 \%$ for male and $80.9 \%$ for female cases and $75.3 \%$ for male and $71.7 \%$ for female referents respectively.

\section{Biomedical measures}

A clinical examination including measurement of blood pressure and blood sampling (after overnight fasting) was conducted for non-fatal cases and referents at least three months after disease onset. High density lipoprotein (HDL) cholesterol was measured according to Warnick, ${ }^{16}$ and low density (LDL) lipoprotein was measured according to Fridewald's formula ${ }^{17}$ (for detailed description see references ${ }^{4}{ }^{14}$ ).

\section{Questionnaire information}

In addition to the clinical examination standardised questionnaire information on medical history including hypertension, hyperlipidaemia, diabetes, and coronary heart disease was available. Type and duration of medication, cigarette smoking (numbers per day, smoking history), and physical exercise (type and frequency) were also assessed with the help of tested standardised questions.

Information on job strain and effort-reward imbalance was obtained from standardised questionnaires. Job strain was measured by the Karasek demand-control questionnaire containing four point Likert scaled items ranging from never to almost always. ${ }^{318}$ Five items addressed demands and six items focused on decision latitude. Cronbach's $\alpha$ ranges from 0.61 to 0.75 for job demands and from 0.68 to 0.86 for decision latitude among men. ${ }^{41}$ Among women respective values range from 0.51 to 0.72 for demands and from 0.73 to 0.85 for decision latitude. ${ }^{19}$ To define job strain a ratio of demands and decision latitude was calculated according to a procedure used in recent studies: the sum score measuring demands is divided by the sum score measuring decision latitude with higher 
values indicating higher decision latitude; people in the upper quartile of this job strain ratio are defined as exposed. ${ }^{414}{ }^{10}$ The upper quartile is defined using the distribution of the job strain ratio among the referents.

Effort-reward imbalance was measured by a standardised questionnaire containing 42 Likert scaled items. The extrinsic (situational) component of the model was assessed by 13 items measuring the frequency of time pressure, high responsibility, overtime work and increasing responsibility (factor extrinsic effort), the frequency of esteem by colleagues and superiors, and insufficient career reward (job insecurity and undesirable job change) (factor occupational reward). This part of the questionnaire was not identical with the original items measuring occupational effort and reward, but was shown to be a useful proxy measure of the extrinsic model component. ${ }^{1321}$ However, psychometric properties of the two factors were less satisfying (Cronbach's $\alpha=0.32$ for effort and 0.37 for reward) than those of the original factors in other ongoing studies (Cronbach's $\alpha=0.71$ for effort and 0.80 for reward). According to the theoretical formulation a ratio of effort (nominator) and reward (denominator) was calculated to assess the degree of imbalance between high cost and low gain at work where a value $>1.0$ indicates the critical condition. ${ }^{1322}$

Information on the personal or intrinsic component of the model, the coping pattern overcommitment, was assessed by a psychometric test composed by 29 Likert scaled items. Confirmatory factor analyses of three different large datasets testing the unidimensionality of the construct found evidence for this solution although the goodness of fit was not optimal $(\mathrm{GFI}=0.76-0.81)$. Cronbach's $\alpha$ of this scale was 0.77. A sum score of the intrinsic component measuring overcommitment was computed. According to test statistical indication, a score ranging in the upper tertile (=13, scale range $0-29)$ was considered a psychosocial risk condition as several independent studies documented increased cardiovascular risk in subjects whose scores exceeded this threshold. ${ }^{813}$

As situational and personal components are clearly distinct at the conceptual and at the operational level, the relative contribution of each component to an explanation of adverse health can be assessed in quantitative terms. Finally, it is important to mention that the operationalisation of either job stress model was independent from each other.

Among cases all questionnaire information was retrospectively related to the time before disease onset.

Table 1 describes cases and referents in terms of core variables measuring sociodemographic characteristics, cardiovascular risk factors, and job stress. The higher mean blood pressure among referents may be explained the hospitalisation of cases after acute myocardial infarction and related antihypertensive medication. Yet, the proportion of hypertensives is higher among cases because of the fact that subjects taking antihypertensive medication on a regular basis were defined as belonging to the group of hypertensives.

\section{Statistical analysis}

Multivariate logistic regression models were calculated to answer the research questions. Subjects with missing data were excluded listwise- that is, people with missing information on at least one of the items in analysis were excluded. This procedure may result in a slight change of subject numbers in either logistic regression model according to the variables included. The model fit was estimated with the help of the Likelihood ratio difference test. ${ }^{23}{ }^{24}$ All analyses were performed separately for men and women controlling for the following confounders: smoking (current, ex smokers, never smoker), lack of physical exercise ( < twice/week), body mass index $\left(>27 \mathrm{~kg} / \mathrm{m}^{2}\right)$, hypertension (WHO criteria), total cholesterol $(>5.68 \mathrm{mmol} / \mathrm{l})$, family history of coronary heart disease (yes/no), and history of diabetes (yes/no). Possible statistical first order interaction effects between confounders and job stress indicators were tested. As hospital catchment area and age were neither associated with the exposure nor changed the risk estimation concerning the psychosocial exposures both variables were excluded from analysis.

Multivariate analysis was performed in three steps. Firstly, the effect of job strain and effort-reward imbalance on acute myocardial infarction was calculated separately-that is, not adjusting for the other model (tables 2 and 3). Secondly, the association between effort-reward imbalance, job strain and acute myocardial infarction was estimated while adjusting each job stress model for the other (table 4). This procedure permits the testing of the independent contribution of either model to the risk estimation of acute myocardial infarction. Thirdly, to test the combined effect of effort-reward imbalance and job strain on myocardial infarction distinct exposure groups were computed (table 5): (1) unexposed: neither effort-reward imbalance nor job strain present; (2) effortreward imbalance present but job strain absent; (3) job strain present but effort-reward imbalance absent; (4) both effortreward imbalance and job strain present. The strongest effect on acute myocardial infarction is expected for category (4). Because of expected gender-specific effects of effort-reward imbalance $^{13}$ the two measures of effort-reward imbalance were combined with job strain in different regression models. Accordingly, effects of the above mentioned four exposure groups were calculated in separate models stratified for gender: (a) model I for the combination of the effort-rewardratio and the job strain ratio, and (b) model II for the combination of overcommitment and the job strain ratio.

\section{RESULTS}

Associations between the two components of the effortreward imbalance model and acute myocardial infarction are shown in table 2. In men the measure of the extrinsic component (that is, the effort-reward-ratio) is associated with increased risk of acute myocardial infarction after adjustment for different confounders. Odds ratios are 1.41 and 1.58 respectively. Yet, the association of the intrinsic component

Table 2 Logistic regression analyses: associations between indicators of effort-reward imbalance and myocardial infarction (men and women aged 45-64 years) (multivariate odds ratios $(95 \% \mathrm{Cl})$, number of exposed)

\begin{tabular}{|c|c|c|}
\hline & Men & Women \\
\hline \multicolumn{3}{|c|}{ Effort-reward ratio (>1) (extrinsic model component) } \\
\hline adjustment* & $1.41(1.05$ to 1.89$) n=250$ & $0.92(0.53$ to 1.61$) n=74$ \\
\hline adjustment† & $1.58(1.16$ to 2.15$) n=247$ & $0.73(0.40$ to 1.33$) n=74$ \\
\hline \multicolumn{3}{|c|}{ Overcommitment (upper tertile) (intrinsic model component) } \\
\hline adjustment* & $1.23(0.96$ to 1.59$) n=392$ & $1.68(1.07$ to 2.62$) n=135$ \\
\hline adjustment $\dagger$ & $1.11(0.85$ to 1.45$) n=389$ & $1.49(0.93$ to 2.41$) n=135$ \\
\hline
\end{tabular}

*Adjusted for effort-reward-ratio or overcommitment respectively and hypertension, total cholesterol, diabetes family history of CHD; tadditionally adjusted for cigarette smoking (never/former/current), BMI $\geqslant 27$, lack of physical exercise $(<2 /$ week). 
Table 3 Logistic regression analyses: associations between job strain and myocardial infarction (men and women aged 45-64 years) (multivariate odds ratios $(95 \% \mathrm{Cl})$, number of exposed)

\begin{tabular}{lll}
\hline Job strain present & Men & Women \\
\hline Adjustment* & $1.39(1.08$ to 1.78$) n=371$ & $1.68(1.12$ to 2.51$) n=186$ \\
Adjustment & $1.45(1.11$ to 1.89$) n=367$ & $1.39(0.90$ to 2.16$) n=186$ \\
\hline
\end{tabular}

*Adjusted for hypertension, total cholesterol, diabetes, family history of CHD; †additionally adjusted for cigarette smoking (never/former/current), BMI $\geqslant 27$, lack of physical exercise (<2/week).

Table 4 Logistic regression analyses: associations between indicators of job stress (effort-reward imbalance and job strain adjusted for each other) and myocardial infarction (men and women aged 45-64 years) (multivariate odds ratios $(95 \% \mathrm{Cl})$, number of exposed)

\begin{tabular}{lll}
\hline & Men & Women \\
\hline $\begin{array}{l}\text { Adjustment* } \\
\text { effort-reward ratio (>1)(extrinsic model component) }\end{array}$ & $1.34(0.99$ to 1.82$) n=250$ & $0.81(0.45$ to 1.44$) n=74$ \\
$\begin{array}{l}\text { overcommitment (upper tertile) (intrinsic model component) } \\
\text { Job strain (present) }\end{array}$ & $1.18(0.92$ to 1.53$) n=390$ & $1.50(0.95$ to 2.37$) n=134$ \\
$\begin{array}{l}\text { Adjustment } \\
\text { effort-reward ratio (>1) (extrinsic model component) }\end{array}$ & $1.48(1.07$ to 1.71$) n=359$ & $1.60(1.03$ to 2.49$) n=182$ \\
$\begin{array}{l}\text { overcommitment (upper tertile) (intrinsic model component) } \\
\text { Job strain (present) }\end{array}$ & $1.08(0.82$ to 1.42$) n=244$ & $0.67(0.36$ to 1.26$) n=73$ \\
\hline
\end{tabular}

*Adjusted for each other and additionally adjusted for and hypertension, total cholesterol, diabetes, family history of CHD; tadditionally adjusted for cigarette smoking (never/former/current), BMI $\geqslant 27$, lack of physical exercise (<2/week).

(that is, overcommitment) with the outcome remains statistically insignificant. In contrast, in women overcommitment is associated with acute myocardial infarction after adjustment for hypertension, total cholesterol, history of diabetes, and coronary heart disease (odds ratio 1.68) whereas no influence of the effort-reward ratio is observed. Yet, the association of overcommitment with myocardial infarction in women seems to be affected by behavioural risk factors as indicated by decreasing risk estimations after additional adjustment for smoking, lack of physical exercise, and body mass index.

Table 3 displays findings concerning the job strain model. Among both men and women job strain is associated with acute myocardial infarction. Whereas this association remains significant in men after adjustment for confounders (odds ratios are 1.39 and 1.45 respectively), significance disappears in women by taking particular behavioural risk factors into account (odds ratios 1.68 and 1.39 respectively).
To test the independent association of either job stress model with acute myocardial infarction effort-reward imbalance and job strain were adjusted for each other and additional confounders. As can be seen from table 4 no significant contribution neither of effort-reward imbalance nor of job strain is found among men after adjustment (1). Additional adjustment for behavioural cardiovascular risk factors (adjustment (2)) shows a significant contribution of the effort-reward ratio to the risk estimation of acute myocardial infarction. Among women only job strain is associated with the outcome after controlling for both components of the effort-reward imbalance model and additional confounders (adjustment (1)). No significant contribution of job stress among women is found after adjustment (2).

To answer the second question of this study information on the two job stress models was combined to estimate odds ratios of acute myocardial infarction. Table 5 shows respective

Table 5 Logistic regression analysis: Combined effect of effort-reward imbalance and job strain on risk of myocardial infarction (multivariate odds ratios $(95 \% \mathrm{Cl})$, number of exposed)

\begin{tabular}{|c|c|c|c|c|}
\hline & \multicolumn{2}{|l|}{ Men } & \multicolumn{2}{|l|}{ Women } \\
\hline & adjustment $\left({ }^{*}\right)$ & adjustment ( $t)$ & adjustment $\left({ }^{*}\right)$ & adjustment ( $t)$ \\
\hline \multicolumn{5}{|l|}{ Model I } \\
\hline $\begin{array}{l}\text { neither effort-reward-ratio }>1 \text { nor job strain present } \\
\text { effort-reward-ratio }>1 \text { but job strain absent }\end{array}$ & $\begin{array}{l}1.00 n=805 \\
1.31 \quad(0.87 \text { to } 1.97) \\
n=115\end{array}$ & $\begin{array}{l}1.00 n=796 \\
1.42(0.92 \text { to } 2.18) \\
n=114\end{array}$ & $\begin{array}{l}1.00 n=238 \\
0.49(0.18 \text { to } 1.37) \\
n=23\end{array}$ & $\begin{array}{l}1.00 n=235 \\
0.50(0.17 \text { to } 1.44) \\
n=23\end{array}$ \\
\hline job strain present but effort-reward-ratio $\leqslant 1$ & $\begin{array}{l}1.28(0.93 \text { to } 1.74) \\
n=216\end{array}$ & $\begin{array}{l}1.30(0.94 \text { to } 1.82) \\
n=214\end{array}$ & $\begin{array}{l}1.45(0.90 \text { to } 2.34) \\
n=124\end{array}$ & $\begin{array}{l}1.31(0.78 \text { to } 2.20) \\
n=124\end{array}$ \\
\hline effort-reward-ratio $>1$ AND job strain present & $\begin{array}{l}1.75(1.18 \text { to } 2.59) \\
n=132\end{array}$ & $\begin{array}{l}2.02(1.34 \text { to } 3.07) \\
n=130\end{array}$ & $\begin{array}{l}1.53 \text { (0.77 to } 3.03 \text { ) } \\
n=50\end{array}$ & $\begin{array}{l}1.05(0.50 \text { to } 2.19) \\
n=50\end{array}$ \\
\hline \multicolumn{5}{|l|}{ Model II } \\
\hline $\begin{array}{l}\text { neither overcommitment nor job strain present } \\
\text { overcommitment present but job strain absent }\end{array}$ & $\begin{array}{l}1.00 n=683 \\
1.25(0.92 \text { to } 1.71) \\
n=237\end{array}$ & $\begin{array}{l}1.00 n=675 \\
1.20(0.86 \text { to } 1.66) \\
n=235\end{array}$ & $\begin{array}{l}1.00 n=196 \\
1.52(0.82 \text { to } 2.03) \\
n=62\end{array}$ & $\begin{array}{l}1.00 n=196 \\
1.19(0.62 \text { to } 2.30) \\
n=62\end{array}$ \\
\hline job strain present but overcommitment absent & $\begin{array}{l}1.36(0.97 \text { to } 1.89) \\
n=196\end{array}$ & $\begin{array}{l}1.51(1.05 \text { to } 2.15) \\
n=193\end{array}$ & $\begin{array}{l}1.62(0.95 \text { to } 2.76) \\
n=102\end{array}$ & $\begin{array}{l}1.23(0.69 \text { to } 2.20) \\
n=102\end{array}$ \\
\hline overcommitment AND job strain present & $\begin{array}{l}1.49(1.01 \text { to } 2.18) \\
n=152\end{array}$ & $\begin{array}{l}1.31(0.88 \text { to } 1.97) \\
n=151\end{array}$ & $\begin{array}{l}2.47 \text { (1.33 to } 4.59) \\
n=72\end{array}$ & $\begin{array}{l}2.19(1.11 \text { to } 4.28) \\
n=72\end{array}$ \\
\hline
\end{tabular}

*Adjusted for effort-reward-ratio or overcommitment respectively and hypertension, total cholesterol, history of diabetes, family history of CHD †Additionally adjusted for smoking (non-smoker, ex smoker, current smoker), lack of physical exercise, BMI. 
findings in separate analyses for men and women. As described in the Methods section two logistic regression models were estimated: in model I the combination of the effortreward ratio with job strain was analysed, in model II the combination of overcommitment with job strain was explored. Table 5 shows that, among men, acute myocardial infarction risk is increased in the group characterised simultaneously by an increased effort-reward ratio $(>1.0)$ and job strain ratio (upper quartile) (odds ratio 1.72 and 2.35) compared with the remaining groups. As suggested at the beginning of the article, risk estimation based on a combination of the two job stress models results in relatively consistent effects (model I: effort-reward imbalance and job strain in men). In women, after full statistical adjustment, a similar association is not found.

With regard to overcommitment and job strain (model II) reversed gender specific effects are observed: in women, the group characterised by overcommitment (upper tertile) and job strain ratio (upper quartile) exhibits an increased acute myocardial infarction risk (OR 2.23) compared with the remaining groups. Risk estimation based on a combination of the two job stress models, again, results in relatively consistent associations between job stress and myocardial infarction (model II: overcommitment and job strain in women). In men, after full adjustment, similar associations are not observed.

\section{DISCUSSION}

Results of this large representative case-control study support earlier prospective and cross sectional observations of increased cardiovascular risk and disease rates in employees exposed to a stressful psychosocial work environment as measured by two complementary job stress models. In particular, three findings became evident in this study. Firstly, job strain was associated with increased odds ratios of acute myocardial infarction in men and, to a lesser extent, in women, whereas the two components of the effort-reward imbalance model were associated with myocardial infarction risk according to gender: among men, the effort-reward ratio (situational component) contributed significantly, among women, overcommitment, the personal component, contributed significantly to the risk estimation. Secondly, controlling for each job stress model respectively resulted in an independent effect of the effort-reward ratio on risk estimation among men whereas no association of the components of the two models with cardiovascular risk was found among women, after extensive controlling for confounders. Thirdly, this study showed that by combining information from the two models estimation of disease risk can be substantially improved. Additional analyses controlling for socioeconomic group and for full time compared with part-time work did not change these results.

\section{Validity of measures}

It has been argued that self report measures of job stress are subject to substantial measurement bias, particularly so in retrospective investigations such as the current case-control study. Therefore, validation efforts are particularly important. As self reported information among cases was collected after a clinical manifestation of myocardial infarction recall of previous stressful circumstances may have biased the findings.

We cannot rule out this argument. However, the findings of this study are in line with a body of evidence derived from prospective epidemiological investigations. ${ }^{389}$ Moreover, in both models, highly aggregated measures of job stress were constructed by the researchers using standard procedures based on theoretical considerations (effort-reward ratio, sum score overcommitment, job strain ratio). It is unlikely that variation in recall bias between cases and referents varies systematically according to these aggregate measures. In addition, previous investigations studying the confounding effects of distinct psychological characteristics of respondents (for example, negative affectivity, neuroticism, depressive mood) ${ }^{9}$ and of knowledge about one's health condition ${ }^{8}$ found little impact on the robustness of findings.

Several investigations compared expert based ratings of job strain ${ }^{9}$ or inferred measures of job strain based on a work exposure matrix ${ }^{425}$ with self report measures. Sensitivity and specificity of self reports and inferred measures with regard to myocardial infarction were found to be similar in cases as compared with controls. ${ }^{4}$ Further support for the internal consistency and the predictive validity of self reported job strain measures can be obtained from a recent report on psychometric information of these measures. ${ }^{25}$

The validity of effort-reward imbalance measures is substantiated by a number of recent (partially unpublished) findings. They concern (a) the replication of the factorial structure of measures across different populations; (b) the ability of the model's components to explain a range of health outcomes $^{10}$; and (c) the correspondence of self report measures with externally assessed working conditions. ${ }^{782126}$

\section{Combination of models}

In a commentary Kasl noted that comparisons of different job stress models with regard to health outcomes are needed to advance the current state of the art. ${ }^{27}$ The independent contribution of either job stress model towards explaining new reports of coronary heart disease has been analysed in one investigation, the Whitehall II prospective cohort study by adjusting the effect of one model for the other.' Similar findings were obtained with regard to subjective indicators of wellbeing. ${ }^{28}$ Yet, no attempt was made to combine the information from the two models in distinct exposure groups to improve statistical prediction. ${ }^{9}$ Consequently, this was done in this study. This statistical approach is different from adjusting - that is, weighting the effects of one model for the effect of the other one-as each subject is exclusively defined by one of the four categories of the respective exposure variable (see table 4). Accordingly, this procedure provides a more conservative risk estimation. Further support of this approach is given by the fact that no overlap between measures of the two models did exist in our analyses-that is, the two models represent distinct conceptual and operational approaches, and correlations between scales from the two models were found to be low, with the exception of a moderate correlation between demand and effort, varying between $r=0.32$ and $r=0.50$.

Previous investigations combining the two models observed an improved prediction or explanation of health indicators. ${ }^{98}$ However, these studies were based on the confounding approach mentioned. Moreover, one study was conducted in a relatively homogeneous occupational population ${ }^{9}$ and, at least in one investigation, health criteria were not as objective as in this report, and measures of the intrinsic model component were not included. ${ }^{28}$ Regarding gender specific results the observed association of overcommitment with cardiovascular risk among women is in accordance with previously reported findings from another large epidemiological study. ${ }^{9}$ These findings call for further analyses with particular emphasis on gender roles. They also suggest that additional factors not analysed in this study may be important in affecting cardiovascular health in women, such as extra work stressors or their cumulation with adverse working conditions, lack of control in general life, multiple role obligations, and limited resources. ${ }^{13}$ 30-33

\section{Limitations of the study}

Several limitations need to be taken into account. Although the study sample is representative of the total work force in Stockholm county it consists of an urban, north western European work force characterised by an overall high level of 
education and a relatively low degree of income inequality. This work force may not adequately reflect the full amount of work related stress that is experienced among populations characterised by more pronounced socioeconomic differences and exposed to more powerful labour market dynamics. But even so, associations of psychosocial work stress with coronary heart disease in this report may be underestimated as young victims of myocardial infarction ( $<45$ years) were excluded. Young victims were found to be characterised by pronounced work related stress experience. ${ }^{15}$ It is unlikely that the restriction to non-fatal cases led to a survival bias influencing the associations under study. Additional analyses showed no difference between fatal and non-fatal cases regarding exposure to objectively measured job strain and related risks of acute myocardial infarction.

Unselected missing data mainly caused by a lack of information from the clinical screenings led to a reduced number of subjects who entered multivariate analyses (tables 2 to 5) compared with the original sample. Yet, no difference between the original sample and the reduced sample was found with regard to psychosocial exposure prevalence and to case/referent status. Therefore it is unlikely that the reduced numbers of subjects in multivariate analysis affected the associations under study.

Furthermore, the inclusion of socioeconomic group as confounder in additional multivariate analysis did not affect the results of this study. Yet, it should be mentioned that our definition of socioeconomic group (that is, white collar versus blue collar) does not cover the whole range of social inequality indicators although it defines an important part of socioeconomic status.

As mentioned, the extrinsic part of the measures of effortreward imbalance at work was not identical with the original measures. Only a reduced number of items was included mainly because of practical constraints in view of the large sample size. The reduced number of items in these proxy measures may be responsible for the relatively low reliability of respective scales. This holds particularly true as information obtained from these items has been dichotomised (see Methods section). With few binary items in a scale only relatively low Cronbach's $\alpha$ values can be expected. ${ }^{34}$ Thus, we cannot rule out the assumption that improved measures - that is, full application of original measures, might contribute to a more adequate estimation of the risk.

Nevertheless, further independent prospective assessment of the predictive validity of information derived from a combination of the two work stress models is needed before policy implications of reported results for the design of work site health promotion measures can be addressed.

In conclusion, to our knowledge, this is the first report demonstrating improved estimation of risk of documented acute myocardial infarction by combining information from two complementary job stress models, the job strain model and the effort-reward imbalance model. Although recall bias resulting from the case-control design of the study cannot be ruled out findings point to the promise of comparing and combining conceptually different job stress models in studies of occupational health.

\section{ACKNOWLEDGEMENTS}

We appreciate the critical comments of an anonymous reviewer to an earlier version of this manuscript.

Funding: we thank the German Science Foundation for supporting this investigation (no SI 236/7-1).

Conflicts of interest: none.

\section{Authors' affiliations}

R Peter, Department of Medical Sociology, University of Ulm, Germany J Siegrist, Department of Medical Sociology, University of Duesseldorf,
Germany

J Hallqvist, Department of Public Health Sciences, Division of Social

Medicine, Karolinska Institute, Stockholm, Sweden

C Reuterwall, Department of Epidemiology/NSVO, Karolinska Hospital, Norrbacka-KS, Sweden

T Theorell, National Institute for Psychosocial Factors and Health,

Stockholm, Sweden

The SHEEP Study Group, Karolinska Institute: Institute of Environmental Medicine, Department of Public Health Sciences, Units of Social Medicine and Occupational Health, and Department of Medical Epidemiology; National Institute for Working Life, Department of Occupational Health;

National Institute for Psychosocial Factors and Health; Stockholm County

Council: Departments of Environmental Medicine, Epidemiology,

Occupational Health, and Social Medicine; the Departments of Medicine at Danderyd, Huddinge, Löwenströmska, Nacka, Norrtälje, Sabbatsberg St Görans, Södersjukhuset, and Södertälje Hospital, and the Departments of Cardiovascular Medicine and Clinical Chemistry, Karolinska Hospital (all at hospitals in the County of Stockholm, Sweden).

\section{REFERENCES}

1 Karasek RA, Theorell T. Healthy work: stress, productivity, and the reconstruction of working life. New York: Basic Books 1990.

2 Schnall PL, Landsbergis PA, Baker D. Job strain and cardiovascular disease. Annu Rev Public Health 1994;15:381-411.

3 Theorell T, Karasek R. Current methodological issues relating to psychosocial job strain and cardiovascular disease research. J Occup Health Psychol 1996;1:9-26.

4 Theorell T, Tsutsumi A, Hallqvist J and the SHEEP study group. Decision latitude, job strain, and myocardial infarction: a study of working men in Stockholm. Am J Public Health 1998:88:382-8.

5 Hallqvist J, Diderichsen F, Theorell T and the SHEEP Study Group. Is the effect of job strain on myocardial infarction risk due to interaction between high psychological demands and low decision latitude? - Results from the Stockholm Heart Epidemiology Program (SHEEP). Soc Sci Med 1998:46:1405-15.

6 Belkic K, Landsbergis $P$, Schnall P, et al. Psychosocial factors: review of the empirical data among men. In: Schnall P, Belkic K, Landsbergis P, et al, eds. The workplace and cardiovascular disease. Occupational Medicine, State of the Art Reviews 2000;15:24-46.

7 Siegrist J. Adverse health effects of high-effort/low-reward conditions. J Occup Health Psychol 1996;1:27-41.

8 Siegrist J, Peter R, Junge A, et al. Low status control, high effort at work and ischemic heart disease: prospective evidence from blue-collar men. Soc Sci Med 1990:31:1127-34.

9 Bosma H, Peter R, Siegrist J, et al. Two alternative job stress models and the risk of coronary heart disease. Am J Public Health 1998;88:68-74.

10 Peter R, Siegrist J. Chronic psychosocial stress at work and cardiovascular disease: the role of effort-reward imbalance. Int J Law Psychiatry 1999:22:441-9.

11 Hall EM. Gender, work control and stress: a theoretical discussion and an empirical test. Int J Health Serv 1989;19:725-45.

12 Orth-Gomer K, Chesney MA. Social stress/strain and heart disease in women. In: Desmond GJ, Wenger NK. Women and heart disease. Guildford: Biddles, 1997:407-20.

13 Peter R, Alfredsson L, Hammar N, et al. High effort, low reward and cardiovascular risk factors in employed Swedish men and women baseline results from the WOLF- Study. J Epidemiol Community Health 1998,52:540-7.

14 Reuterwall C, Hallqvist J, Ahlbom A, et al. Higher relative but lower absolute risks of myocardial infarction in women than in men: analysis of some major risk factors in the SHEEP Study. J Int Med 1999;246:16174

15 Johnson JV, Hall E, Theorell T. Combined effects of job strain and socia isolation on cardiovascular disease morbidity and mortality in a random sample of the Swedish male working population. Scand J Work Environ Health 1989;15:271-9.

16 Warnick GT. Colirometric assessment of high density lipoprotein cholesterol. In: Cooper GR, ed. Selected methods of clinical chemistry. Washington DC: American Association for Clinical Chemistry, 1983;10:91-9.

17 Abell LL, Levy BB, Brodie BB, et al. A simplified method for the estimation of total cholesterol in serum and demonstration of its specifity. J Biol Chem 1951;195:357.

18 Theorell T, Perski A, Akerstedt T, et al. Changes in job strain in relation to changes in physiological state: a longitudinal study. Scand J Work Environ Health 1988;14:189-96.

19 Karasek RA, Brisson C, Kawakami N, et al. The Job Content Questionnaire (JCQ): a instrument for internationally comparative assessments of psychosocial job characteristics. J Occup Health Psychol 1998;3:322-55

20 Knutsson A, Hallqvist J, Reuterwall C, et al. Shiftwork and myocardial infarction: a case-control study. Occup Environ Med 1999;56:46-50.

21 Matschinger $\mathbf{H}$, Siegrist J, Siegrist K, et al. Type A as a coping career: towards a conceptual and methodological redefinition. In: Schmidt TH, Dembroski TM, Blümchen $G$, eds. Biological and psychological factors in cardiovascular disease. Berlin: Springer, 1986:104-26.

22 Peter R, Alfredsson L, Knutsson A, et al. Is a stressful psychosocial work environment mediating the effects of shiftwork on cardiovascular risk factors in men? Scand J Work Environ Health 1999;25:376-81. 
23 Efron B. The efficiency of logistic regression compared to normal discriminant analysis. Journal of the American Statistical Assocociation 1975;70:892-8.

24 Hosmer DW, Lemeshaw S. Applied logistic regression. New York: Wiley, 1989

25 Johnson JV, Stewart W, Hall EM, et al. Long-term psychosocial work environment and cardiovascular mortality among Swedish men. Am J Public Health 1996;86:324-31.

26 Peter R. Berufliche Belastungen, Belastungsbewältigung und koronares Risiko bei Industriearbeitern (Work stress, coping behaviour, and coronary risk among blue-collar workers). Hamburg Münster: Lit, 1991.

27 Kasl S. Influence of the work environment on cardiovascular health: a historical, conceptual, and methodological perspective. J Occup Health Psychol 1996;1:42-56.

28 De Jonge J, Bosma H, Peter R, et al. Job strain, effort-reward imbalance and employee well-being: a large-scale cross-sectional study. Soc Sci Med 2000;50: 1317-27.
29 Marmot MG, Bosma H, Hemingway H, et al. Contribution of job control and other risk factors to social variations in coronary heart disease incidence. Lancet 1997;350:235-9.

30 Davey Smith G, Harding S. Is control at work the key to socioeconomic gradients in mortality? (letter). Lancet 1997;350:1369-70.

31 Arber S, Gilbert N, eds. Women and working lives: divisions and change. London: Macmillan, 1991.

32 Pugh H, Moser K. Measuring women's mortality differences. In: Roberts H, ed. Women's health counts. London: Routledge, 1990:93-112.

33 Wamala SP. Socioeconomic status and cardiovascular vulnerability in women. [Thesis.] Stockholm: Karolinska Institutet, Department of Public Health Sciences, Division of Preventive Medicine, Huddinge-Stockholm, Sweden, 1999

34 Kim JO, Muller CW. Factor analysis. Statistical methods and practical issues. Beverly Hills: Sage, 1978.

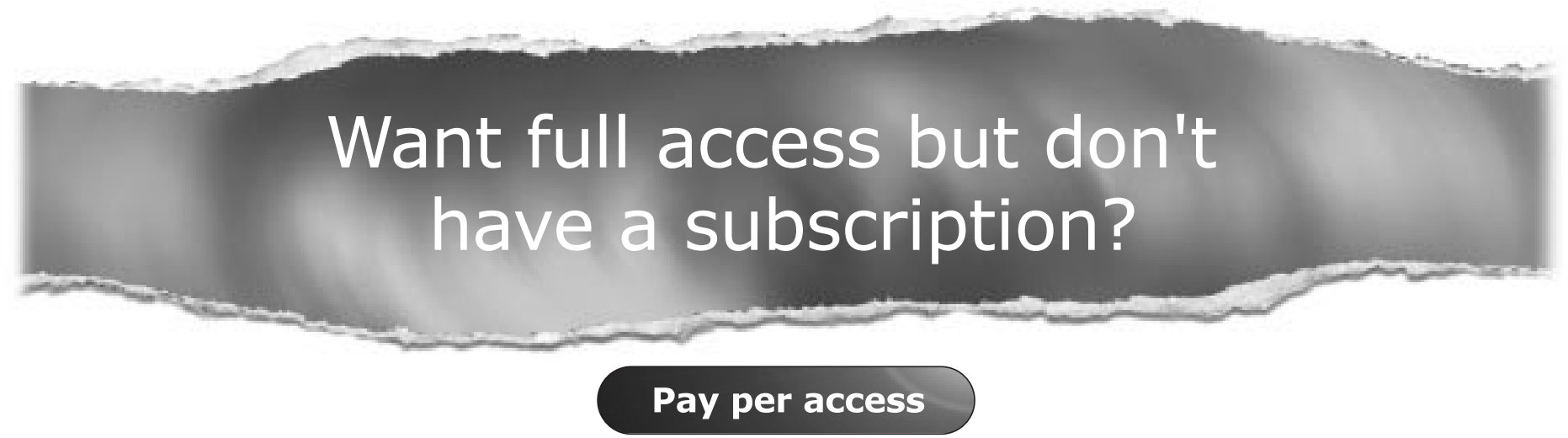

For just US $\$ 25$ you can have instant access to the whole website for 30 days. During this time you will be able to access the full text for all issues (including supplements) available. You will also be able to download and print any relevant pdf files for personal use, and take advantage of all the special features Journal of Epidemiology and Community Health online has to offer. 